\title{
Study of power system stability: Matlab program processing data from Zahrani power plant (Beirut, Lebanon)
}

\author{
Fouad Alhajj Hassan ${ }^{1}$ and Alexander Sidorov \\ Department of Electrical Engineering, Kazan State Power Engineering University, Kazan 420066, Russia
}

\begin{abstract}
Stability is of great importance in power systems; instability can cause fluctuations in many parameters of a power system. Since the purpose is to keep feeding the load when a fault or disturbance of overload occurs, the main attention will be focused on over-voltage and frequency because they might make a great damage and shutdown the system. In this study, calculations were performed for one machine connected to infinite bus, considering steady state and transient stability using Matlab to achieve a stable system.
\end{abstract}

\section{Introduction}

The development of electrical power systems during the past couple of years resulted in the development of the system instability too. To keep dealing with problems such as faults and disturbances; new technologies and methods of analysis were invented, in order to supply the loads and keep the system secured. However, power system stability is known as the capability of an electric power system, for a given starting operating conditions, to recover a state of operating balance after being subjected to a physical disorder, with most system variables enclosed so that the entire system remains unharmed. The system will fail to regain equilibrium if it is unstable. Instability exists in many kinds of modern power systems, such as voltage and frequency; accordingly, there are different methods used to solve them. The stabilization processes works by compensating the causes of instability [1].

\section{Classification of power stability}

Power stability can be classified into different types, namely:

- Angle stability

- Voltage stability

- $\quad$ Frequency (mid and long term) stability

- Small-signal (dynamic) stability: Determines if the system remains in synchronism after a small disturbance (e.g, small load and/or generation variations).

- Transient stability: Determines if the system remains in synchronism after a significant disturbance (e.g, transmission fault, sudden load change, loss of generation, line switching).

- $\quad$ First-swing stability: Performs system analysis for the 1 st second after a system fault (simple generator model \& no control model).
- $\quad$ Multi-swing stability: Performs system analysis over a long period of time (more sophisticated machine model)

Different types of stability are summed up in the following block diagram, shown in figure 1 .

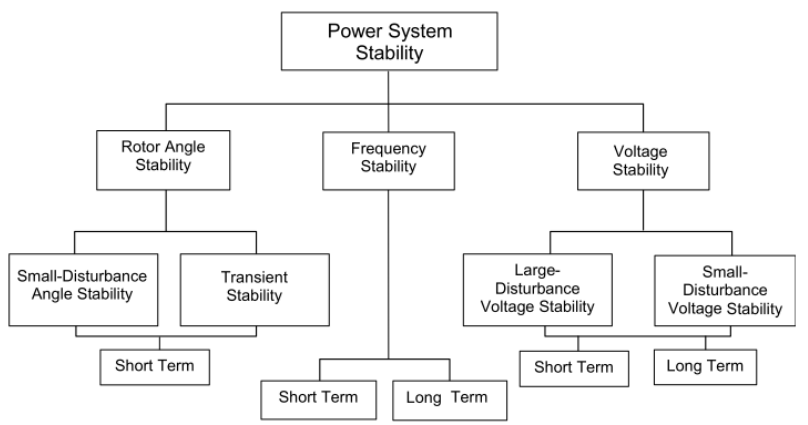

Fig. 1. Classification of Power System Stability $[2,3]$.

\subsection{Rotor Angular or Synchronous Stability}

The rotor angle stability issue includes the investigation of electromechanical oscillations inalienable in power systems. A critical factor in this problem is how the power outputs of synchronous machines fluctuate as their rotor angles change. In case when the system is irritated, this balance is disturbed, which results in speeding up or deceleration of the machines rotors as indicated by the laws of movement of a turning body. In case if one generator incidentally runs faster than the other one, the angular position of its rotor with respect to that of the slower machine will progress. Past a specific point of confinement, an expansion in the precise partition is joined by a diminishing in power exchange; this builds the angular division further and prompts to instability. It ought to be noticed that loss of synchronism can happen between one machine and whatever remains of the system, or between groups of

* Corresponding author: FouadHajjHassan42@gmail.com 
machines, probably with synchronism preserved within each group after untying from each other. [4,5]

\subsection{Frequency Stability}

Frequency stability is subjected to the ability of a power system to hold steady frequency following a brutal system upset resulting in a significant difference between generation and load. It depends on the ability to keep up/re-establish the balance between system generation and load, with the least unexpected loss of load. The instability that may occur as a result of managed frequency swings, which results in stumbling of creating units or potentially loads. Extreme system disturbance results in huge trips of frequency, power flow, voltage, and other system variables, accordingly summoning the activities of procedures, controls, and protection that are not displayed in routine transient stability or voltage stability studies. In large interconnected power systems, this sort of circumstance is most regularly connected with conditions taking after part of systems into islands. Stability for this situation is an issue of regardless of whether every island will achieve a condition of equilibrium with insignificant inadvertent loss of load. For the most part, frequency stability issues are connected with deficiencies in hardware reactions, poor coordination of control and protection equipment, or lacking generation reserve $[6,7]$.

\subsection{Voltage Stability}

When it comes to reactive power balance, the circumstance is not as clear and straightforward as concerning active power. There is dependably a harmony amongst the "delivered" and "expended" reactive power in each hub of a network. This is an immediate result of the Kirchhoff's first current law. When one discusses irregularity in this setting, it will imply that the infused reactive power is such, typically too little, that the voltage in the hub cannot be kept to adequate qualities. (At low load the infused reactive power could be high bringing about a too high voltage, conceivably higher than the hardware may be intended for. This is obviously not desirable, but rather it could ordinarily be controlled in a manner that no instabilities develop.) When discussing imbalance for this situation, the infused reactive power contrasts from the coveted infused reactive power, expected to keep the desired voltage. In the event that this imbalance gets too high, the voltages surpass the satisfactory range $[8,9]$.

\section{One machine stability flow chart}

One machine stability is classified into four cases: damping, Euler's, Equal area criteria with and without fault.

\subsection{Damping case and Euler method flow charts}

The flow chart of one machine stability in case of damping is interpreted as follows: first, the input data is entered to the MATLAB program, then the data got involved in the swing equation, and then damping ratio's effect is included into the formula, and the result got displayed as data and graphs.

Euler's method tends to know the accelerated power angle and speed by estimating the slope of the power. After loading the 11 column data, the program is run and the results will show power angle and frequency variation numerically, and in figures.

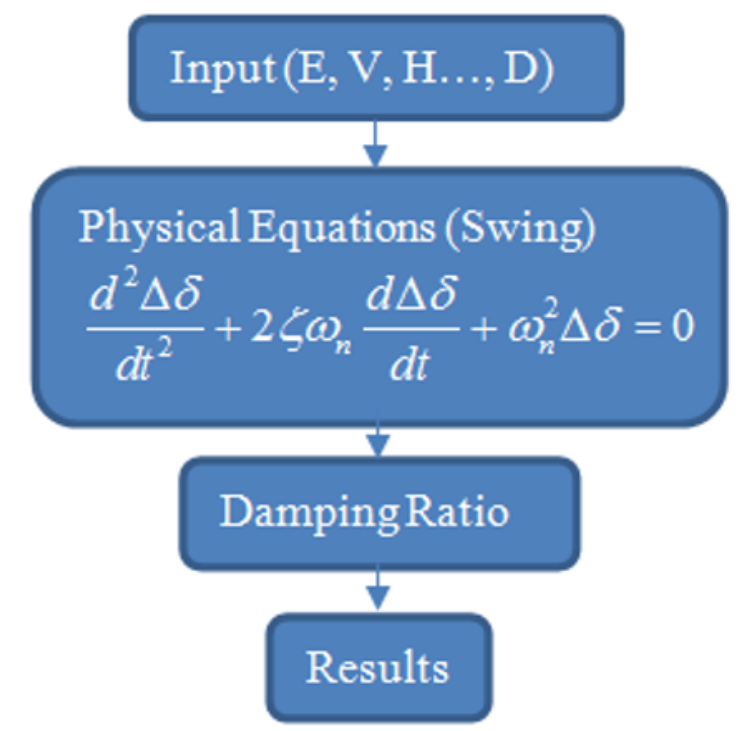

Fig. 2. Damping case flow chart.

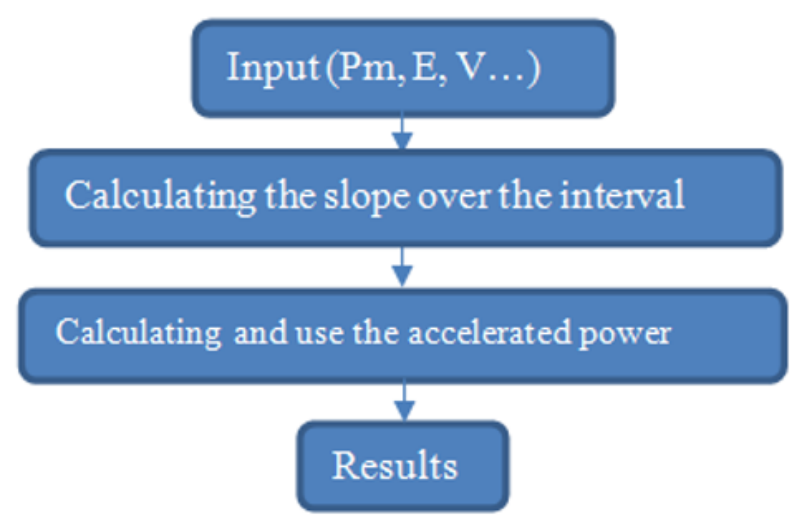

Fig. 3. Euler method flow chart.

\subsection{Equal area criterion with and without fault}

In this methodology, the power system got defined so that the program can continue its process, then the input data are entered and the branch number that is predicted to be faulted is entered and checked for faults. If it detects a fault, then calculations are performed to check the time needed to eliminate the fault and the results are displayed. While if no fault is detected, then the branch will get eliminated from the study and power calculations are carried out to obtain the results. 


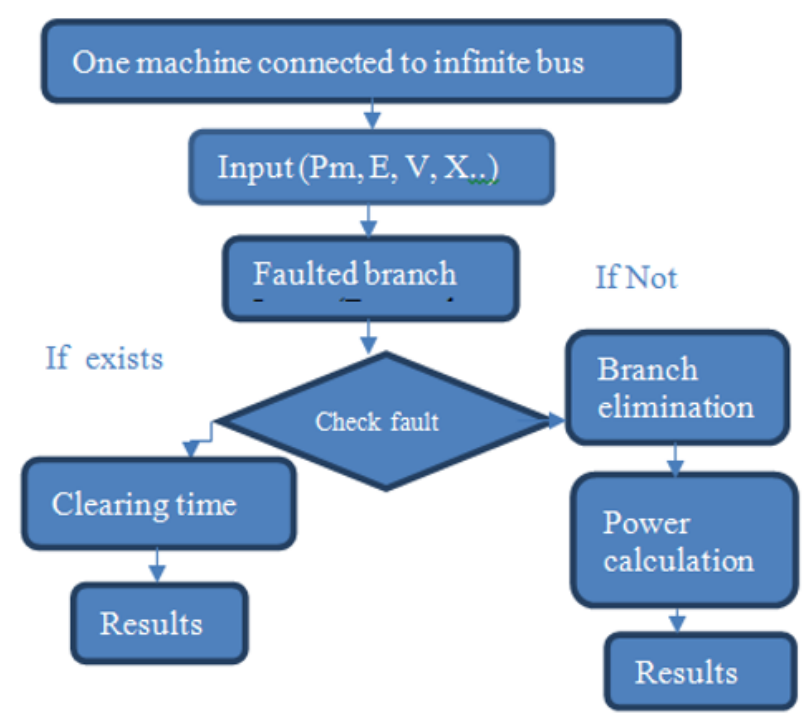

Fig. 4. Equal area criterion flow chart.

\section{Case study}

The case study is made for the Zahrani power plant. Data were taken as the inputs, and implemented using Graphical User Interface (GUI). Results are shown to display the most severe fault case.

Methods for one machine are applied below (Damped, Euler, Equal area without or with fault).

\subsection{One machine in case of damping}

When the generator deviates from its synchronous speed of $3000 \mathrm{rpm}$, frequency is modified to $50 \mathrm{~Hz}$ to include a damping torque of $0.35 \mathrm{pu}$.

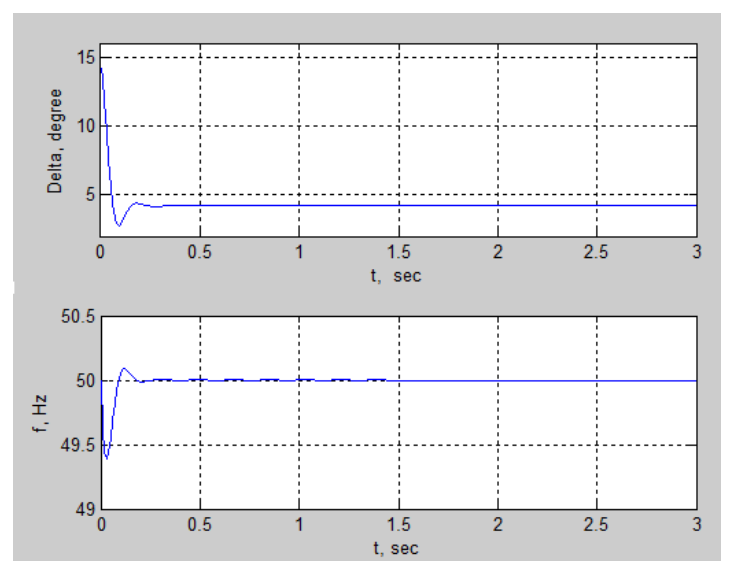

Fig. 5. Relationship between the power angle Delta and the frequency obtained using damping theory for inputs per unit, $\mathrm{E}=1.6$, Vload=1, $\mathrm{H}=1.52, \mathrm{Pm}=1, \mathrm{~F}=50 \mathrm{~Hz}, \mathrm{X}=2.03$.

\subsection{One machine Euler's method}

After applying two derivation on swing equation, with $\mathrm{Pm}$ reference, $\mathrm{E}=1.6 \mathrm{pu}, \mathrm{V}=1 \mathrm{pu}, \mathrm{X} 1=2 \mathrm{pu}, \mathrm{X} 2=0.5 \mathrm{pu}$, $\mathrm{X} 3=0.94 \mathrm{pu}, \mathrm{H}=1.52 \mathrm{pu}, \mathrm{F}=50 \mathrm{~Hz}, \mathrm{Tc}=0.4 \mathrm{~s}, \mathrm{Tf}=1 \mathrm{~s}$, Tstep $=0.002 \mathrm{~s}$. At $0.4 \mathrm{~s}$, the average power angle and frequency are decreased.

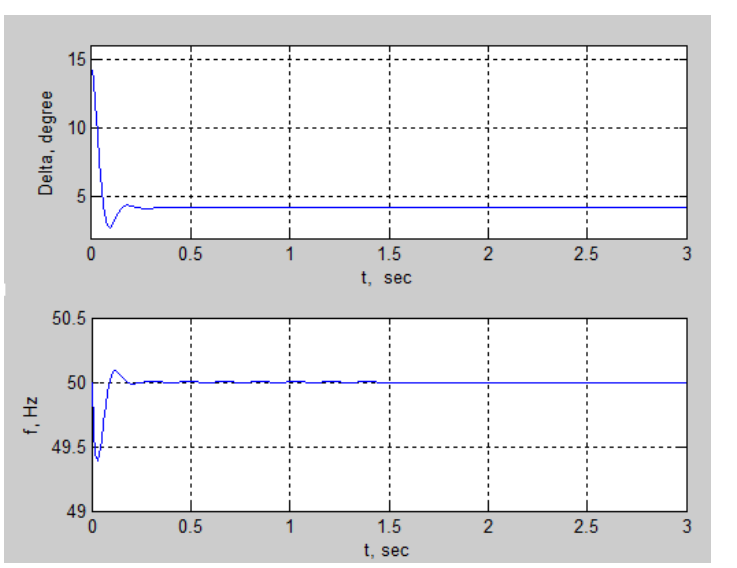

Fig. 6. Relationship between the power angle Delta and the frequency obtained using the Euler's method.

\subsection{Equal are criteria without or with Fault}
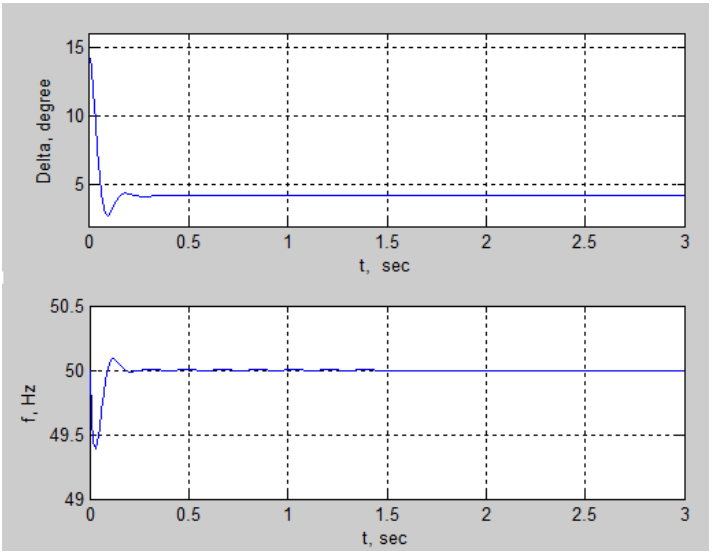

Fig. 7. Relationship between the power angle Delta and the frequency obtained using the Equal Area Theory.

\section{Conclusion}

According to the presented data, the following specs should be taken into consideration in order to keep the power system stable:

- Increment of the inertia constant of the generators. This makes the rotors harder to accelerate regarding faults, and the hazard for losing synchronism is lessened. As a rule, this is an extremely costly means, and just in unique cases, it can be connected, e.g. by introducing a flywheel on a little hydro unit.[10]

- Increment of system voltage. This builds $P_{e \max }$, and for a given power $P_{m}$ the stability margins are expanded $[11,12]$.

- Decrease of the transfer reactance $X_{e}$. This will likewise increase $P_{e \max }$ as in the past case. This can be accomplished by building parallel lines, or by introducing series capacitors on existing lines or new lines. By introducing series capacitors, the effective reactance of the line is decreased. This strategy has been utilized broadly throughout the years $[13,14]$. 
Establishment of quick securities and quick breakers. Along these lines, the time with a fault associated can be lessened and in this manner the time during which the generator rotors are quickened. The capability for the system to decelerate the rotor swings is increased [15].

\section{References}

1. K. Prabha, Power System Stability and Control, 7, 271 (1993)

2. K. Prabha, P. John, A. Venkat, A. Göran, B. Anjan,N. Claudio, H. Nikos, H. David, S. Alex, T. Carson, V.C. Thierry, V. Vijay, Definition and Classification of Power System Stability, IEEE TRANSACTIONS ON POWER SYSTEMS, 19, 4 (2004)

3. A. Bashar, G. Chin, Power System Frequency Stability and Control, Survey International Journal of Applied Engineering Research, 11, 5689 (2016)

4. S. Priyank, P. Rashmi, A review on power system stability and applications of fact devices, International Journal of Engineering Research and Applications, 3, 879-880 (2013)

5. R. Oscar, S. Jon, B. Pavol, Small-signal modelling and stability analysis of a traditional generation unit and a virtual synchronous machine in gridconnected operation supervisor Elisabetta $T$ cosupervisors, 9 (2015)

6. T. Simon, Eds. E. Habil, Eds. S. Mohamed, Oscillatory Stability Assessment of Power Systems using Computational Intelligence supervisor, Dissertation, 12 (2005)

7. IEEE Power Engineering Society 2002 IEEE Guide for Synchronous Generator Modeling Practices and Applications in Power System Stability Analyses ed Catherine B and Dom M (3 Park Avenue, New York, NY 10016-5997, USA) The Institute of Electrical and Electronics Engineers, Inc. chapter, 3, 4

8. P. Kessel, H. Glavitsch, Estimating the Voltage Stability of a Power System, IEEE Transactions on Power Delivery, 1, 346 (1986)

9. V.C. Thierry, V. Costas, Voltage Stability of Electrical Power Systems, Springer Science+Business Media, 1, 4 (1988)

10. A. Goran, Power System Analysis ETH Zurich Eidgenossische Technische, 127 (2012)

11. S. Abri, S. Ehab, A. Yasser, Optimal Placement and Sizing Method to Improve the Voltage Stability Margin in a Distribution System Using Distributed Generation, IEEE TRANSACTIONS ON POWER SYSTEMS Vol 28, 2 (2013)

12. H.H. Goh, Q.S. Chua, S.W. Lee, B.C. Kok, K.C. Goh, K.T. Teo, Power Stability Monitoring Based on Voltage Instability Prediction Approach Through Wide Area System, American Journal of Applied Sciences, 729 (2014)

13. K. Edward, Eds. A. Paul, Power system stability: Elements of stability calculations, 1 (1995)

14. P. Suguna, G. Rasmitha, Reactive Power Compensation and Load Balancing of Multi Area
Power System by SVC and Active Filter, International Journal of Innovative Technology and Exploring Engineering (IJITEE), 8, 1032-1037 (2019)

15. A. Bose, C. Concordia, R.D. Dunlop, A.A. Fouad, P. Kundur, R.P. Schulz, Proposed Terms \& Definitions For Power System Stability. IEEE Transactions on Power Apparatus and Systems, PAS-101, 1897 (1982) 